in the study of endocrine disorders florid excess has often been the starting point from which subtle interrelationships of mediator and target have been deciphered.

1 Verner, J V, and Morrison, A B, American fournal of Medicine, 1958, 25, 374

2 Said, S I, and Muff, V, Science, 1970, 169, 1217.

${ }^{3}$ Barbezat, G O, and Grossman, M I, Science, 1971, 174, 422

4 Schorr, B A, Said, S I, and Makhlouf, G M, Clinical Investigation, 1974, $22,23$.

${ }^{5}$ Kerins, C, and Said, S I, Proceedings of the Society for Experimental Biology and Medicine, 1973, 142, 1014.

${ }^{6}$ Makhlouf, G M, Said, S I, and Yau, W M, Gastroenterology, 1974, 66, 737.

' Bloom, S R, Polak, J M, and Pearse, A G E, Lancet, 1973, 2, 14.

${ }^{8}$ Said, S I, and Faloona, G R, New England fournal of Medicine, 1975, 293, 155.

${ }^{9} \mathrm{Kraft}, \mathrm{A} \mathrm{R}$, Tompkins, R K, and Zollinger, R M, American fournal of Surgery, 1970, 119, 163.

\section{Fractures of the shaft of tibia}

Fractures of the shaft of the tibia are caused principally by road accidents, accidents at work, and accidents in sport. Yet in spite of their frequency the treatment of these fractures remains controversial and the results variable.

The surgeon treating a fracture of the tibial shaft is faced with three problems: the slow rate of union, the high incidence of delayed and non-union compared with other fractures, and the difficulty of controlling radiological and anatomical deformity. The factors influencing the rate of union are no different from those applying to other fractures, but the tibia is unusually prone to compound injury. Soft tissue damage with skin loss, difficulties of skin closure at operation, and a risk of osteomyelitis are all factors adversely affecting the chances of primary union.

All surgeons agree that compound wounds should be debrided and the skin over the fracture closed without tension where possible. Tetanus toxoid and a course of suitable antibiotics should be given. Most surgeons agree that delayed and non union should be treated surgically; but timing of such operative intervention is less certain, as are the indications for the use of internal fixation or bone grafts or both.

Even in fresh fractures the differences of opinion are reflected in the diversity of the methods of treatment. Tibial shaft fractures can be treated conservatively or operatively. Even this dichotomy is not the only problem, for members of each school apply the doctrines in various ways. The conservative method of treatment includes reduction (and traction if necessary) and an above-knee plaster-of-Paris with or without early weight bearing. Some surgeons try to preserve the mobility of the knee, particularly in low tibial fractures, by applying a suitably shortened plaster. Others support the Hoffman method of rigid external fixation using pins inserted through the bone proximal and distal to the fracture. This method is specially useful in controlling fractures in legs where there has been skin loss or damage, for it allows access to the area for dressing.

Surgical methods in current use include open and closed nailing, plating with or without compression or bone grafting, amputation, and encirclage wiring. The last method is mentioned only to be condemned, for though it produces radiological accuracy the wires act like a tourniquet on the bone, interfering with the local blood supply and delaying or preventing union. The Swiss AO group are strong advocates of internal fixation, and have done much to simplify and improve the technique. Paradoxically, this advance has caused problems- for the technical simplicity of internal fixation may tempt the untrained surgeon into rash operative adventures.

As Nicoll $^{1}$ has stressed, the aims of internal fixation should be a reduction in the incidence of functionally significant deformity and joint stiffness, and a reduction in the risks of delayed and non-union; these advantages must be clear enough to outweigh the risks of surgery. Charnley's ${ }^{2}$ warning should be heeded: failures of operative and conservative treatment are not equally salvageable by secondary procedures. Adding his weight to the conservative school, Van der Linden et $a^{3}$ have developed an earlier report about skiing fractures of the tibial shaft. He and his co-workers compared fractures from skiing injuries with those from road accidents, from other sports, from accidents at work, and those in a miscellaneous group of all other cases. There were 393 skiing fractures and 207 fractures from other causes; $85 \%$ of the total were treated conservatively by reduction and a long leg plaster. Surgery was undertaken only when conservative treatment failed or when it was thought that it would fail.

Van der Linden et al found that fractures due to skiing accidents healed faster than in any other group and that the patient could be mobilised quicker and returned to work sooner. This was true of patients of any age and of fractures in any part of the tibial shaft, though like Nicoll they found that fractures in the distal third of the tibia healed marginally better than fractures in the other two-thirds. Most skiing fractures occur in the distal third of the tibia, but Van der Linden $^{4}$ does not believe this to be the reason for their improved prognosis. He argues that skiing injuries tend to produce low energy fractures; there is rarely any direct violence to the skin or soft tissues; and that compound fractures are rare. The fragments are only a little displaced, and finally the people in whom these fractures occur tend to be in better health than the population at large.

Olerud and Karlstrom ${ }^{5}$ have obtained good results from compression osteosynthesis in longitudinal fractures caused by direct violence of low energy, but this may be no more than confirmation that such fractures do well with any treatment, conservative or operative. Thus a surgeon operating on a tibial fracture of this type need concern himself only with avoidance of complications. Furthermore, the argument that internal fixation allows early mobilisation does not apply to tibial fractures: for, unlike patients with fractures of the femoral shaft, they can be mobilised early in plaster with crutches.

1 Nicoll, C A, Fournal of Bone and foint Surgery, 1964, 46B, 373.

2 Charnley, J, The Closed Treatment of Common Fractures. 4th ed. London and Edinburgh, Churchill Livingstone, 1970.

3 Van der Linden, W, Sunzel, H, and Larsson, K, fournal of Bone and foint Surgery, 1975, 57A, 321.

4 Van der Linden, W, Acta Orthopaedica Scandinavica, 1970, 40, 797.

5 Olerud, S, and Karlstrom, G, Acta Orthopaedica Scandinavica, 1972, suppl. No 140 .

\section{In the public interest}

The profession must "keep its cool." Nothing will encourage the Government and its supporters more in the burgeoning dispute over the future of independent medical practice than for doctors to sound off with emotional, unreasoned statements. The Government's intentions ${ }^{1}$ are not a burning political issue for a public whose most immediate worry is inflation. So the profession will have to be skilful, constructive, and calm if it is to convince people that Mrs Castle's con- 